\title{
The Effects of Cord Clamping Time and Early Skin-to-Skin Contact on Maternal Birth Satisfaction in Term Infants
}

\author{
Kubra Genc ${ }^{1}$ (D) Ayse Karakoc $^{2}$ (D) Taner Celikel $^{1}$ (D) \\ ${ }^{1}$ Kocaeli Fatih Public Hospital, Istanbul, Turkey. \\ ${ }^{2}$ Marmara University Faculty of Health Sciences Midwifery Department, Istanbul, Turkey. \\ Correspondence Author: Ayse Karakoc \\ E-mail: akarakoc@marmara.edu.tr \\ Received: 05.11.2019 Accepted: 06.07.2020
}

\begin{abstract}
Objective: Meeting the expectations of mothers during labor is defined as birth satisfaction. Evaluation of women's perception of satisfaction at birth is an important quality criterion in the evaluation of services. This study aims to determine the effect of cord clamping time and early skin contact on maternal birth satisfaction.

Methods: Randomized controlled experimental study. The study data were collected between June and December 2018 , from a total of 80 participants.

Results: Case group was applied late cord clamping and skin contact, control group was applied routine care. The first breastfeeding time was $11.20 \pm 5.16 \mathrm{~min}$. for the case group and $44.55 \pm 18.03 \mathrm{~min}$. for the control group $(p<0.001)$. Neonatal blood glucose levels within the first 15 minutes were $91.23 \pm 20.61 \mathrm{mg} / \mathrm{dL}$ for the case group and $83.13 \pm 14.17 \mathrm{mg} / \mathrm{dL}$ for the control group ( $p=0.044)$. Hemoglobin levels of the newborn 24 hours after birth were $18.90 \pm 1.58 \mathrm{~g} / \mathrm{dL}$ for the case group and $18.13 \pm 1.78 \mathrm{~g} / \mathrm{dL}$ for the control group ( $\mathrm{p}=0.042$ ). The difference between the before and after birth hemoglobin-hematocrit values of the mothers was not statistically significant ( $p=0.327$ for $\mathrm{Hgb}$; $p=0.238$ fot $\mathrm{Htc}$ ). Postpartum satisfaction levels of the mothers were found to be $106.28 \pm 9.52$ for the case group and $99.93 \pm 13.17$ for the control group; mothers at the case group had higher postpartum satisfaction levels ( $p=0.016)$.
\end{abstract}

Conclusion: Late cord clamping and early skin contact in newborn positively affect the first breastfeeding time, hemoglobin, hematocrit and blood sugar levels of newborns and can be considered as an important factor that increases mothers' satisfaction independent of many variables.

Keywords: Newborn, late cord clamping, skin to skin contact, maternal birth satisfaction.

\section{INTRODUCTION}

The World Health Organization (WHO) recommends 1-3 minutes postpartum as the cord clamping time for all nonasphyxic newborns that do not require resuscitation (1). According to the routine approach in Turkey, it is considered appropriate to keep the umbilical cord at the baby-perineum level $(30-45 \mathrm{sec})$ due to the risk of polycythemia and hyperbilirubinemia.

The mother and the baby should not be separated from each other within the first two hours after birth and should spend this time in skin contact with each other. Weighing, measuring, dressing, performing the first examination, etc., which requires separation from the mother. procedures should be performed at the end of the monitoring period in the delivery room, after two or three hours. Immediate skin to skin contact (SSC) after birth was associated with stable body temperature, stable blood glucose level, less crying, less respiratory distress, earlier and more effective sucking, and longer breastfeeding time (2).
Meeting the expectations of mothers during labor is defined as birth satisfaction. Every woman's expectation from birth is different and each woman's satisfaction varies according to different characteristics. Evaluation of women's perception of satisfaction at birth is an important quality criterion in the evaluation of services. Increasing the quality of maternity services and reducing the cost per patient has become a health policy adopted by all countries of the world $(3,4)$.

Giving birth is an important experience in women's life. A traumatic birth experience may pose a risk to problems such as post-partum depression, post-traumatic stress disorder, sexual dysfunction, Cesarean section, inadequate maternal attachment and infant neglect (5-7).

Demographic characteristics of the mother, mode of delivery, planning of delivery, hospital environment and facilities, attitudes and behaviors of health personnel, and the effects of various factors such as prenatal education have been 
evaluated in the studies conducted on birth satisfaction and results vary (8-14).

The effects of Early Cord Clamping (ECC) and early skin-to-skin contact (SSC) are popular research topics in recent years, but there are not any studies being conducted on the effects of these on maternal satisfaction. In this respect, this research would contribute to the literature. The aim of this study is to determine the effects of ECC and early SSC on maternal birth satisfaction in term infants.

\section{METHODS}

This is a randomized controlled experimental study conducted determine the effects of cord clamping time and early skin contact on maternal birth satisfaction in term infants. The table of random numbers was used in line with the simple random sampling method.

A total of 80 mothers and infants were included in the study, 40 in the control group and 40 in the case group. In the mothers included in the case group, the umbilical cord was cut after waiting for 1-3 minutes (mean 2 minutes) according to WHO recommendations and the newborn was laid naked in the mother's chest for the first 15 minutes. During the procedure, the baby's back was wrapped with a heated cover and the headgear was dressed. First breastfeeding and skin contact was provided. Measurements of height, weight, and head circumference, and administration of vitamin $\mathrm{K}$ and Hepatitis B vaccine were performed after the completion of skin-to-skin contact. Data were collected in the first 15 minutes, during the SSC. In the control group, the umbilical cord was cut within 30 seconds after the baby was born in accordance with routine hospital practices, and the routine care of the newborn was performed under a radiant heater.

\subsection{Participants}

The study data were collected between May 2018 and December 2018 from pregnant women who met the inclusion criteria and accepted to be involved in the study. The study sample consisted of 901 pregnant women who admitted to the state hospital for labor and delivery in the previous year. The power of the study was targeted to be $80 \%$ and $\alpha=0.05$, and the sample size was calculated. In the study, type I error was limited to 0.05 and type II error rate was limited to 0.20 . Under these conditions, the minimum number of subjects required for each group was determined to be 37 in order to find a significant difference of 5.00 units between the two groups. The study was completed with 80 mothers (Consort Diagram: Appendix 1).

The inclusion criteria consisted of 'primiparous and multiparous mothers aged $18-38$ years without any risk during pregnancy and postpartum' and 'healthy term babies born at term (38-42 weeks) and 2500-4000 g, with Apgar score above 7, with no need for resuscitation and any congenital anomalies'.

\subsection{Data Collections and Tools}

General Information Form, Maternal and Newborn Data Form, and Birth Satisfaction Scale (BSS) were used for data collection. General Information Form includes questions regarding the socio-demographic characteristics of the participants such as age, gender, marital status, education level, occupation, and number of children. Maternal and Newborn Data Form includes questions such as the mother and the baby's vital signs in the first 24 hours after the birth, the first breastfeeding time, and the Apgar score (Appendix 2).

BSS was developed by Caroline Hollins Martin and Valerie Fleming in 2011 to assess women's perceptions of birth (15). Validity and reliability were not made in the first form. Martin et al. revised the scale in 2014 and did a validity and reliability study, and reported the Cronbach's alpha value as 0.79 (16). Cetin et al. (2015) performed the validity and reliability study of the first version of the scale in Turkish Language (3). It is a 5-point Likert type scale and scored as follows: Strongly agree: 5, Agree: 4, Undecided: 3, Disagree: 2, Strongly disagree: 1 . Items 4, 8, 12, 15, 16, 17, 19, 20, 21, $23,25,29$ are scored in reverse. The scale has 30 items and the score can vary between $30-150$ points, and the higher the score, the higher the satisfaction with birth. Cronbach's alpha value of the scale was 0.79 in this study.

The following measuring devices were used: Acon Mission $\mathrm{Hb}$ \& Hct Meter, Seca 834 Digital Baby Scale, Clever chek TD4231 Blood Glucose Meter

\subsection{Data Analysis}

In order to test the normality of data distribution, the skewness and kurtosis values were between -1.5 and +1.5 and the data were found to be reliable. The internal consistency coefficient (the Cronbach's alpha value) of the scale was 0.79 . In the study, independent groups t-test was used for comparison of normally distributed binary groups and a non-parametric Mann Whitney $U$ test was used for comparison of non-normally distributed binary groups. In the study, one-way ANOVA analysis was used for comparison of more than two groups with normal distribution, and the nonparametric Kruskal-Wallis $\mathrm{H}$ test was used for comparison of more than two groups that were non-normally distributed.

\subsection{Ethical Considerations}

Approval was received from the Marmara University Faculty of Medicine Clinical Research Ethics Committee on April 6, 2018, with the protocol code 09.2018.274. Verbal and written informed consent was obtained from women who agreed to participate in the study. Permission to use the scale was obtained. 


\section{RESULTS}

In the study, the mean \pm standard deviation (SD) age of the mothers was found to be $27.70 \pm 5.50$ in the case group and $26.67 \pm 4.98$ in the control group. There was no statistically significant difference between the case and control groups in terms of age, education, income level, working status, presence and number of children, family type, presence of chronic disease (diagnosed during pregnancy), Rh incompatibility, number of pregnancies, and gestational week $(p>0.05)$. The demographic characteristics of the two groups were similar.

In Table 1, according to the time of postnatal first breastfeeding the difference between the case group $(11.20$ $\pm 5.16 \mathrm{~min})$ and the control group (44.55 $\pm 18.03 \mathrm{~min})$ was statistically significant $(p<0.001)$. The difference between systolic blood pressure values of the case group mothers $(99.00 \pm 8.41 \mathrm{mmHg}$ ) and the control group mothers (104.25 $\pm 10.83 \mathrm{mmHg}$ ) was statistically significant $(p=0.018)$. At the $60^{\text {th }}$ minute and the $24^{\text {th }}$ hour postpartum measurements, the difference between the pulse rate of the case group and the control group was statistically significant ( $p=0.046$ and $p<0.001$, relatively). The difference between the before and after birth hemoglobin $(\mathrm{Hgb})$ and hematocrit $(\mathrm{Htc})$ values of the mothers was not statistically significant $(p=0.327$ and $p=0.238$, respectively).

Table 1. Comparison of Vital Signs and Blood Values of Mothers

\begin{tabular}{|c|c|c|c|c|c|c|}
\hline \multirow{2}{*}{ Time of Measurement } & \multirow{2}{*}{ Variables } & \multicolumn{2}{|c|}{ Mean \pm SD } & \multirow{2}{*}{$\mathrm{T}$} & \multirow{2}{*}{$S d$} & \multirow{2}{*}{$\mathbf{p}$} \\
\hline & & $\begin{array}{l}\text { Study Group } \\
\qquad \mathrm{n}=40\end{array}$ & $\begin{array}{c}\text { Control Group } \\
n=40\end{array}$ & & & \\
\hline Postpartum & $\begin{array}{l}\text { Time of first breastfeeding } \\
\text { (min) }\end{array}$ & $11.20 \pm 5.16$ & $44.55 \pm 18.03$ & -11.245 & 45.36 & 0.000 \\
\hline \multirow{3}{*}{$\begin{array}{l}\text { Postpartum within the } \\
\text { first } 15 \text { minutes }\end{array}$} & Systolic BP(mmHg) & $99.00 \pm 8.41$ & $104.25 \pm 10.83$ & -2.421 & 78 & 0.018 \\
\hline & Diastolic BP(mmHg) & $63.00 \pm 8.23$ & $64.75 \pm 9.87$ & -0.861 & 78 & 0.392 \\
\hline & Pulse Rate & $79.83 \pm 7.54$ & $80.68 \pm 5.75$ & -0.567 & 78 & 0.572 \\
\hline \multirow{3}{*}{$\begin{array}{l}60^{\text {th }} \text { minute of } \\
\text { postpartum }\end{array}$} & Systolic BP(mmHg) & $101.00 \pm 7.44$ & $103.25 \pm 10.71$ & -1.091 & 69.52 & 0.279 \\
\hline & Diastolic BP(mmHg) & $65.25 \pm 8.16$ & $63.75 \pm 9.25$ & 0.769 & 78 & 0.444 \\
\hline & Pulse Rate/dk & $81.08 \pm 6.78$ & $84.88 \pm 9.00$ & -2.031 & 69.76 & 0.046 \\
\hline \multirow{3}{*}{24 hours after birth } & Systolic BP(mmHg) & $101.10 \pm 9.15$ & $97.15 \pm 16.05$ & 1.352 & 78 & 0.180 \\
\hline & Diastolic BP(mmHg) & $63.00 \pm 6.26$ & $61.70 \pm 9.19$ & 0.739 & 68.81 & 0.462 \\
\hline & Pulse rate/dk & $79.43 \pm 6.85$ & $86.38 \pm 8.95$ & -3.902 & 78 & 0.000 \\
\hline \multirow{2}{*}{$\begin{array}{l}\text { Difference in } \mathrm{Hgb} \text { and } \\
\mathrm{Htc} \text { levels before and } \\
\text { after birth }\end{array}$} & $\mathrm{Hgb}(\mathrm{g} / \mathrm{dL})$ & $1.02 \pm 1.07$ & $0.79 \pm 0.79$ & 0.993 & 39 & .327 \\
\hline & Hct (\%) & $3.97 \pm 5.51$ & $2.42 \pm 5.54$ & 1.197 & 39 & .238 \\
\hline
\end{tabular}

BP: Blood pressure; Hgb:Hemoglobin Htc;Hematocrit

In Table 2, blood glucose values of newborns measured at the first $15^{\text {th }}$ minute after delivery were found to be 91.23 $\pm 20.61 \mathrm{mg} / \mathrm{dL}$ for the case group and $83.13 \pm 14.17 \mathrm{mg} / \mathrm{dL}$ for the control group. The difference between the groups was statistically significant in favor of the case group. The difference between $\mathrm{SpO} 2$ values, $\mathrm{Hgb}$ and $\mathrm{Htc}$ values measured in the newborns at the $24^{\text {th }}$ hour postnatal period was statistically significant in favor of the case group $(p<0.05)$.
In Table 3, maternal BSS scores were $106.28 \pm 9.52$ in the case group and $99.93 \pm 13.17$ in the control group, and the difference between the groups was statistically significant $(p=0.016)$.

The correlation between birth satisfaction score and age, education, working status, presence of child, and family type was found to be statistically insignificant. The increased income status in the control group and the prenatal education satisfaction level in the case group were found to significantly correlate with birth satisfaction score. 
Table 2. Comparison of Vital Signs and Blood Values of Newborns

\begin{tabular}{|c|c|c|c|c|c|}
\hline \multirow[b]{2}{*}{$\begin{array}{c}\text { Time of } \\
\text { measurement }\end{array}$} & \multirow[b]{2}{*}{ Valiables } & \multicolumn{2}{|c|}{ Mean $\pm S D$} & \multirow[b]{2}{*}{$T$} & \multirow[b]{2}{*}{$P$} \\
\hline & & $\begin{array}{c}\text { Study Group } \\
n=40\end{array}$ & $\begin{array}{c}\text { Control Ggroup } \\
n=40\end{array}$ & & \\
\hline \multirow{9}{*}{$\begin{array}{l}\text { Postpartum } \\
\text { within the first } \\
15 \text { minutes }\end{array}$} & APGAR first min. & $9.00 \pm 0.00$ & $8.93 \pm 0.27$ & 1.778 & 0.083 \\
\hline & APGAR $5^{\text {th }} \min$. & $10.00 \pm 0.00$ & $9.93 \pm 0.27$ & 1.778 & 0.083 \\
\hline & $\mathrm{SpO} 2$ & $94.58 \pm 8.97$ & $94.98 \pm 6.85$ & -0.224 & 0.823 \\
\hline & Pulse Rate/dk & $135.50 \pm 13.16$ & $139.38 \pm 7.41$ & -1.622 & 0.109 \\
\hline & Body Temperature $/{ }^{\circ} \mathrm{C}$ & $36.65 \pm 0.29$ & $36.57 \pm 0.21$ & 1.541 & 0.127 \\
\hline & Blood Sugar(mg/dL) & $91.23 \pm 20.61$ & $83.13 \pm 14.17$ & 2.049 & $0.044 *$ \\
\hline & Hemoglobin(g/dL) & $20.31 \pm 1.33$ & $19.93 \pm 1.53$ & 1.172 & 0.245 \\
\hline & Hemotocrit (\%) & $59.73 \pm 3.88$ & $58.70 \pm 4.45$ & 1.098 & 0.275 \\
\hline & Body weight(g) & $3406.75 \pm 354.23$ & $3289.75 \pm 480.77$ & 1.239 & 0.219 \\
\hline \multirow{7}{*}{$\begin{array}{l}24 \text { hours after } \\
\text { birth }\end{array}$} & Body weight(g) & $3237.25 \pm 349.16$ & $3131.75 \pm 472.67$ & 1.135 & 0.260 \\
\hline & $\mathrm{SpO} 2$ & $97.30 \pm 1.07$ & $96.08 \pm 1.89$ & 3.575 & $0.001^{*}$ \\
\hline & Pulse rate/dk & $128.63 \pm 11.25$ & $125.38 \pm 9.45$ & 1.399 & 0.166 \\
\hline & Weight loss(g) & $162.70 \pm 63.19$ & $158.00 \pm 54.64$ & 0.356 & 0.723 \\
\hline & Blood sugar(mg/dL) & $81.45 \pm 9.43$ & $80.20 \pm 14.06$ & 0.467 & 0.642 \\
\hline & Hemoglobin(g/dL) & $18.90 \pm 1.58$ & $18.13 \pm 1.78$ & 2.067 & $0.042 *$ \\
\hline & Hemotocrit (\%) & $55.65 \pm 4.63$ & $53.30 \pm 5.14$ & 2.148 & $0.035^{*}$ \\
\hline
\end{tabular}

Sp02:Blood Oxygen Saturation

Table 3. Comparison of birth satisfaction levels of mothers in the case and the control groups

\begin{tabular}{|c|c|c|c|c|}
\hline \multicolumn{2}{|c|}{ Mean $\pm S D$} & \multirow[b]{2}{*}{$T$} & \multirow[b]{2}{*}{$S d$} & \multirow[b]{2}{*}{$P$} \\
\hline $\begin{array}{l}\text { Experimental } \\
\text { Group }(n=40)\end{array}$ & $\begin{array}{c}\text { Control Group } \\
\quad(n=40)\end{array}$ & & & \\
\hline $106.28 \pm 9.52$ & $99.93 \pm 13.17$ & 2.471 & 70.99 & 0.016 \\
\hline
\end{tabular}

\section{DISCUSSION}

No statistically significant difference was found between the case and the control groups in terms of age, education, income, working status, presence and number of children, family type, chronic disease (diagnosed during pregnancy), Rh incompatibility, number of pregnancies, and gestation week $(p>0.05)$. The demographic characteristics of both groups were similar and the groups were homogeneously distributed.
In the study, the time to start breastfeeding was significantly earlier in the case group $(p<0.001)$. Continuous skin contact until the time of first breastfeeding facilitates breastfeeding and helps the baby gain a better suction technique from the very beginning (2). WHO recommends SSC with the mother during the first hour after birth to prevent hypothermia and to promote breastfeeding in newborns without complications (1).

Similar to the results of the study, in the studies conducted to determine the effect of post-partum early term baby skin contact on breastfeeding; early SSC was reported to have a positive effect on first breastfeeding time and breastfeeding success (17-22).

When the life signs of postpartum mothers were evaluated; control group mothers' systolic blood pressure in the first 15 minutes, and the heart rate after one hour and 24 hours was found to increase significantly. When stress physiology 
is examined, it is stated that there is an increase in heart rate, blood pressure and respiration rate during stress and these values are regulated when coping with stress (23). In this respect, it can be said that the skin contact applied in the early postpartum period facilitates mothers' coping with birth stress. In parallel with the study, with SSC, a reduction in stress responses such as systolic blood pressure and cortisol levels has been reported in preterm infant fathers (24).

The differences between prenatal and postnatal maternal $\mathrm{Hgb}$ and Hct levels were not statistically significant. Similarly, in various studies, no differences were found in $\mathrm{Hgb}$ and $\mathrm{Htc}$ levels of mothers with Late Cord Clamping (LCC) and it was reported that LCC was not associated with postpartum hemorrhage $(25,26)$. In this respect, it can be said that the cord clamping time has no negative effect on postpartum hemorrhage.

Hypoglycemia is frequently observed in healthy newborns as a result of the metabolic adaptation process in the first postpartum hours. Therefore, it is recommended that all babies should be breastfed for the first 30 minutes in the postpartum period (27). SSC at birth also facilitates immediate breastfeeding $(18,19,21)$. In the study, blood glucose levels of the newborns who were treated with SSC at the first hour were found to be significantly higher. In studies examining various parameters of neonatal SSC administered at birth, it was reported that blood glucose levels were significantly safe $(22,28)$.

LCC is recommended by the WHO. In evidence-based studies, it has been emphasized that LCC increases hemoglobin and hematocrit levels and therefore has hematological advantages (25,26,29-33). Similarly, Htc and $\mathrm{Hgb}$ values were significantly higher in the experimental group newborns at the $24^{\text {th }}$ hour postpartum.

Evaluation of satisfaction perception of women at birth is an important criterion in the evaluation of health care. Childbirth is an important experience in women's life, the level of satisfaction in this process is considered important for maternal-newborn health and positive family relationships $(5,8,34)$. As a result of traumatic birth experience in women; post-partum depression, post-traumatic stress disorder may cause problems such as sexual dysfunction, cesarean section, insufficient maternal attachment, and neglect of infants $(5-7,35)$.

In the study, birth satisfaction levels of case group mothers were found to be higher $(p<0.05)$. When mothers' BSS scores were analyzed in terms of demographic characteristics, the relationship between BSS and age, education, working status, presence of child and family type was found to be statistically insignificant. According to the studies, the significance of the factors affecting birth satisfaction varies $(4,8,9,11-14)$.

Limitations: Newborn blood sugar could not be measured at the $6^{\text {th }}$ hour because it was not in hospital routines.

\section{CONCLUSION}

LCC and early skin contact in newborn positively affect the first breastfeeding time, hemoglobin, hematocrit, and blood sugar levels of newborns. It can be said that mothers' satisfaction with birth is affected by too many components, but providing LCC and SSC provides significant efficacy independent of other factors. LCC and early SSC are important factors that increase maternal satisfaction regardless of age, education, working status, and presence of children. We can also say that birth satisfaction is an important factor for strategies to improve perinatal care

Acknowledgment: The data of this manuscript was produced from the master thesis and presented as a verbal presentation at the 10th National Midwifery Students Congress 19-21 April 2019, Sivas/Turkey

\section{REFERENCES}

[1] World Health Organization (WHO). Guideline: Delayed umbilical cord clamping for improved maternal and infant health and nutrition outcomes. Geneva: World Health Organization; 2014. Available from:http:/www.who.int/ nutrition/publications/guidelines date of access 11.03.2019.

[2] Lang C. Bonding, Bindung förderm in der Geburtshilfe. Translation: Uzel N, Ozbalcı S. Bonding. Ankara;Modern Publications, 2018.

[3] Cetin FC, Sezer A, Merih YD. The birth satisfaction scale: Turkish adaptation, validation and reliability study. NCI 2015; 2(2):142-150.

[4] Alfaro Blazquez R, Ferrer Ferrandiz E, Gea Caballero V, Corchon $S$, Juarez-Vela R. Women's satisfaction with maternity care during preterm birth. Birth 2019: 1-8.

[5] Bell AF, Rubin LH, Davis JM, Golding J, Adejumo OA, Carter $\mathrm{CS}$. The birth experience and subsequent maternal caregiving attitudes and behavior: a birth cohort study. Arch Women Ment HIth 2019;22(5):613-620.

[6] Graaff LF, Honig A, van Pampus MG, Stramrood CA. Preventing post-traumatic stress disorder following childbirth and traumatic birth experiences: a systematic review. Acta Obstet Gyn Scan 2018; 97(6): 648-656.

[7] Aydın N, Yıldız H. Effects of traumatic birth experience and transmission intergenerational. JHS 2018;15(1): 604-618 (Turkish).

[8] Altıparmak S, Coşkun AM. Effect of prenatal training on information and satisfaction level of a pregnant woman. JHS 2016;13(2): 2610-2624 (Turkish).

[9] Afshar Y, Mei JY, Gregory KD, Kilpatrick SJ, Esakoff TF. Birth plans-Impact on mode of delivery, obstetrical interventions, and birth experience satisfaction: A prospective cohort study. Birth 2018; 45(1): 43-49.

[10] Mei JY, Afshar Y, Gregory KD, Kilpatrick SJ, Esakoff, TF. Birth plans: what matters for birth experience satisfaction. Birth 2016;43(2): 144-150.

[11] Preis $H$, Lobel $M$, Benyamini $Y$. Between expectancy and experience: testing a model of childbirth satisfaction. Psychol Women Quart 2019; 43(1): 105-117.

[12] Gravensteen IK, Jacobsen EM, Sandset PM, Helgadottir LB, Rådestad I, Sandvik L, Ekeberg $\varnothing$. Anxiety, depression and relationship satisfaction in the pregnancy following stillbirth and after the birth of a live-born baby: a prospective study. BMC Pregnancy Childb 2018; 18(1): 41.

[13] Luegmair K, Zenzmaier C, Oblasser C, König-Bachmann M. Women's satisfaction with care at the birthplace in Austria: 
Evaluation of the babies born better survey national dataset. Midwifery 2018; 59: 130-140.

[14] Bilgin CN, Ak B, Potur CD, Ayhan F. Satisfaction with birth and affecting factors in women who gave birth. HSP. 2018;5(3):342352 (Turkish)

[15] Hollins Martin C, Fleming V. The birth satisfaction scale. Int J Health Care Quality Assurance 2011; 24(2):124-135.

[16] Holins Martin CJ, Martin, CR. Development and psychometric properties of the Birth Satisfaction Scale-Revised (BSS-R). Midwifery 2014;30: 610-619.

[17] Cinquetti M, Colombari AM, Battisti E, Marchetti P, Piacentini $G$. The influence of type of delivery, skin-to-skin contact and maternal nationality on breastfeeding rates at hospital discharge in a baby-friendly hospital in Italy. Pediatr Med Chir 2019;41(1):207

[18] Karimi FZ, Sadeghi R, Maleki-Saghooni N, Khadivzadeh T. The effect of mother-infant skin to skin contact on success and duration of first breastfeeding: A systematic review and metaanalysis. Taiwan J Obstet Gyne 2019;58(1): 1-9.

[19] Widström AM, Brimdyr K, Svensson K, Cadwell K, Nissen E. Skinto-skin contact the first hour after birth, underlying implications and clinical practice. Acta Paediatr. 2019;108(7):1192-1204

[20] Lau Y, Tha PH, Ho-Lim SST, Wong LY, Lim PI, Citra Nurfarah BZM, Shorey S. An analysis of the effects of intrapartum factors, neonatal characteristics, and skin-to-skin contact on early breastfeeding initiation. Matern Child Nutr. 2018;14(1): e12492.

[21] Safari K, Saeed AA, Hasan SS, Moghaddam-Banaem L. The effect of mother and newborn early skin-to-skin contact on initiation of breastfeeding, newborn temperature and duration of third stage of labor. International Breastfeeding Journal 2018;13(1): 32.

[22] Dalsgaard BT, Rodrigo-Domingo $M$, Kronborg $H$, Haslund $H$. Breastfeeding and skin-to-skin contact as non-pharmacological prevention of neonatal hypoglycemia in infants born to women with gestational diabetes; a Danish quasi-experimental study. Sex Reprod Health 2019;19: 1-8.

[23] Ozel $Y$, Karabulut AB. Daily living and stress management. Turkish Journal of Health Sciences and Research 2018;1(1): 48-56 (Turkish).

[24] Varela N, Tessier R, Tarabulsy G, Pierce T. Cortisol and blood pressure levels decreased in fathers during the first hour of skin-to-skin contact with their premature babies. Acta Pediatr. 2018;107(4), 628-632.
[25] Qian Y, Ying X, Wang P, Lu Z, Hua Y. Early versus delayed umbilical cord clamping on maternal and neonatal outcomes. Archives of Gynecology and Obstetrics 2019;300:531-543.

[26] Mohammad K, Tailakh S, Fram K, Creedy D. Effects of early umbilical cord clamping versus delayed clamping on maternal and neonatal outcomes: a Jordanian study. J Matern-Fetal Neo M. 2019;Apr15:1-7.

[27] Aliefendioğlu D, Çoban A, Hatipoğlu N, Ecevit A, Arısoy AE, Yeşiltepe G, Özek E. Approach to hypoglycemia in the newborn: Turkish Neonatal and Pediatric Endocrinology and Diabetes Societies consensus report. Turkish Archives of Pediatrics 2018; 53(1): 224-233.

[28] Koç S, Kaya N. Effect of kangaroo care at birth on physiological parameters of healthy newborns. Turkish Journal of Research \& Development in Nursing 2017;19(1):1-13 (Turkish).

[29] Vatansever B, Demirel G, Ciler Eren E, Erel O, Neselioglu S, Karavar HN, Tastekin A. Is early cord clamping, delayed cord clamping or cord milking best? The J Matern-Fetal Neo M 2018;31(7): 877-880.

[30] Mercer JS, Erickson-Owens DA, Collins J, Barcelos MO, Parker $A B$, Padbury JF. Effects of delayed cord clamping on residual placental blood volume, hemoglobin and bilirubin levels in term infants: a randomized controlled trial. J Perinatol, 2017;37(3), 260.

[31] Mercer JS, Erickson-Owens DA, Deoni SC, Dean DC, Collins J, Parker AB, Padbury JF. Effects of delayed cord clamping on 4-month ferritin levels, brain myelin content, and neurodevelopment: A randomized controlled trial. J Pediatr 2018; 203: 266-272.

[32] Ashish KC, Rana N, Målqvist M, Ranneberg LJ, Subedi K, Andersson $\mathrm{O}$. Effects of delayed umbilical cord clamping early clamping on anemia in infants at 8 and 12 months: a randomized clinical trial. JAMA Pediatrics 2017;171(3): 264270.

[33] Zhao Y, Hou R, Zhu X, Ren L, Lu H. Effects of delayed cord clamping on infants after neonatal period: a systematic review and meta-analysis. Int J Nurs Stud 2019; 92: 97-108.

[34] Göncü SS, Karahan N, Hollins Martin CJ, Martin CR. Construct and content validity of the Turkish Birth Satisfaction ScaleRevised (T-BSS-R). J Reprod Infant Psyc 2018;36(3), 235-245.

[35] Nystedt A, Hildingsson I. Women's and men's negative experience of child birth-A cross-sectional survey. Women Birth 2018;31(2), 103-109. 
Appendix 1. CONSORT Flow Diagram

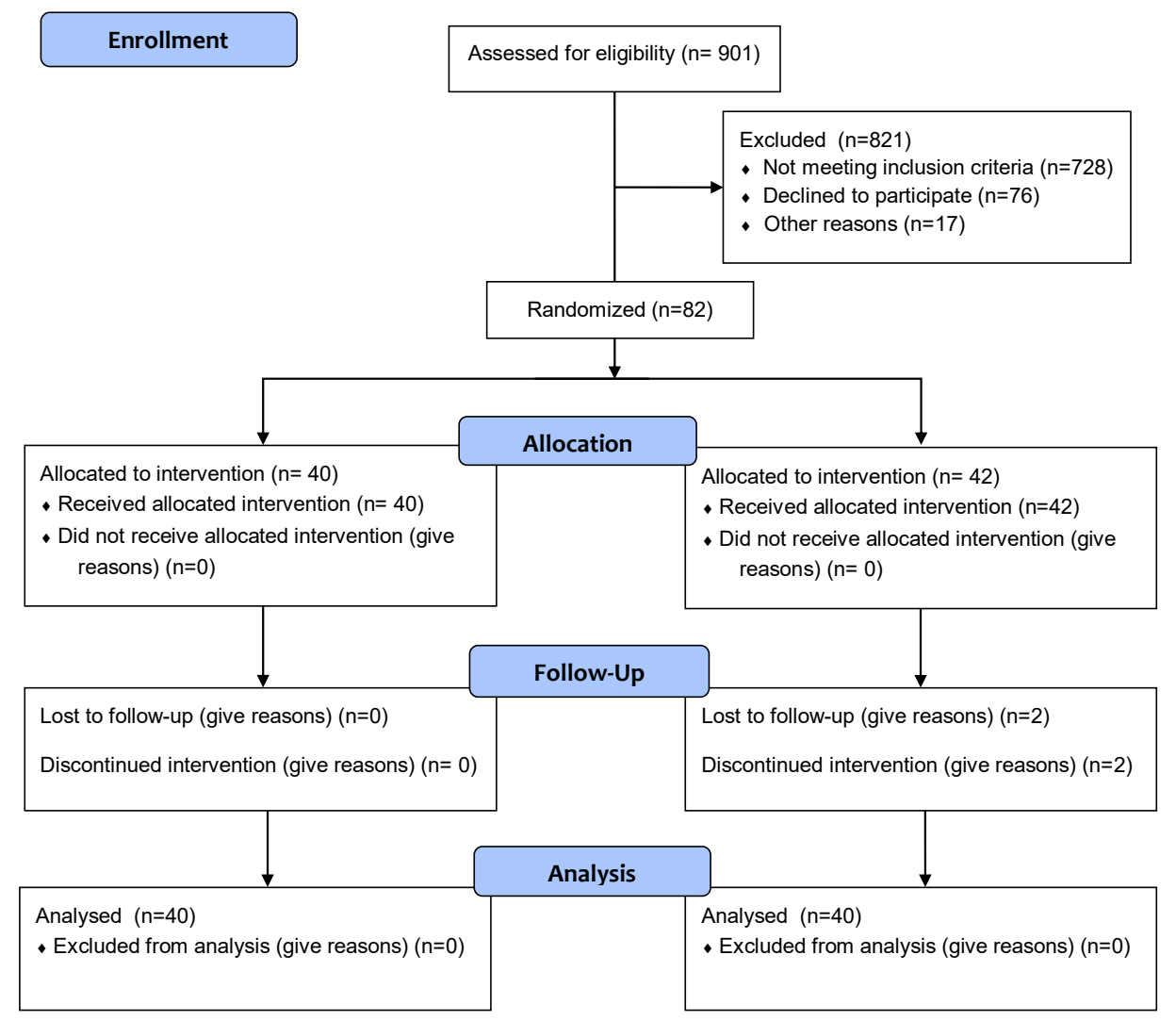

Appendix 2. Data collection planning

\begin{tabular}{|c|c|c|}
\hline & Mothers & Newborns \\
\hline & \multicolumn{2}{|c|}{ Time of first breastfeeding time } \\
\hline Post-partum first 15 minute & $\begin{array}{l}\text { Blood pressure } \\
\text { Pulse rate }\end{array}$ & $\begin{array}{l}\text { APGAR (1-5min) } \\
\mathrm{SpO}_{2} \\
\text { Pulse rate } \\
\text { Body tempature } \\
\text { Blood sugar } \\
\text { Hemoglobin } \\
\text { Hemotocrit }\end{array}$ \\
\hline Postpartum $60^{\text {th }}$ minute & $\begin{array}{l}\text { Blood pressure } \\
\text { Pulse rate }\end{array}$ & Body weight \\
\hline Postpartum $6^{\text {th }}$ hour & $\begin{array}{c}\text { Hemoglobin } \\
\text { Hemotocrit } \\
\text { Bleeding control } \\
\end{array}$ & $\begin{array}{c}\text { Newborn blood sugar could not be measured } \\
\text { at the } 6^{\text {th }} \text { hour because it was not in hospital } \\
\text { routines }\end{array}$ \\
\hline Postpartum $24^{\text {th }}$ hour & $\begin{array}{l}\text { Blood pressure } \\
\text { Pulse rate } \\
\text { Birth satisfaction scale }\end{array}$ & $\begin{array}{c}\text { Body weight } \\
\text { Spo2 } \\
\text { Pulse rate } \\
\text { Blood sugar } \\
\text { Hemoglobin } \\
\text { Hemotocrit } \\
\end{array}$ \\
\hline
\end{tabular}

How to cite this article: Genc K, Karakoc A, Celikel T. The Effects of Cord Clamping Time and Early Skin-to-Skin Contact on Maternal Birth Satisfaction in Term Infants. Clin Exp Health Sci 2020; 10: 355-361. DOI: 10.33808/clinexphealthsci.642377 